\title{
The place and nature of trend forecasting in design debates. An opportunity or threat for design(studies)?
}

This paper examines the place of trend forecasting in contemporary design debates concerning the varying notions of design crafting the future and being a change agent, in order to show the limited understanding of forecasting within these debates. The directive power of trend forecasting remains unacknowledged and therefore underconceptualized in design discourse. It is almost as if forecasting would be an invisible force and an intangible phenomenon. Unacknowledged by critical studies as well, trend forecasting moved from being a prescriptive style advice to a normative practice having effect on major operators of society - another gap this paper indicates. Drawing on empirical research, trend forecasting's trajectory is briefly illustrated. In conclusion this paper discusses whether the integration of such an enlarged understanding of trend forecasting in design studies could deliver an opportunity to enrich discussions on the changing notions of design and even re-gauge the functions of design studies, or whether it is a threat reinforcing the prevalent pluralism within design studies. Finally this paper advocates that only by an in-depth examination of trend forecasting a necessary holistic understanding of this phenomenon can be developed in order to effectively engross these issues.

keywords trend forecasting, design, design studies, change, future

\section{Introduction}

Trend forecasting is a driving force in contemporary creative industries and consumer culture, has effect on major operators of society, and undeniably impacts on change and future - so the thesis of this paper, which is part of theoretical framework of the underlying PhD project: Archaeology of the future - Inside the culture of trend forecasting.' Unacknowledged by current design debates, trend forecasting operates in the same realms where the varying notion of design aims to, i.e. to impact on future and be a driver of change. This paper sheds light on several aspects of this argument: firstly on how the phenomenon of trend forecasting is considered in current design debates around future and change capacities and the normative power of design and secondly gives a brief outline on trend forecasting's current dissemination and entanglement.

Trend forecasting falls in the general category of Futures Studies, an umbrella term for practices studying the future (see: Cole 2001). Futures studies is presented today as a relatively organized practice, with journals, organizations and education programs. 
Figure 1.

Li Edelkoort is one of the most prominent, influential and discussed representatives of the profession of trend forecasting. Source: Elisabeth Petermann, Li Edelkoort speaking at the seminar "Gathering" (20.11.2013, Vienna)
The trend forecasting under study is an envisioning kind of futures studies, which is based on an intuitive, storytelling approach to create future visions rather than on a more scientific one as in, e.g., sales forecasting (see: Cole 2001). One of its most original forms is fashion trend forecasting. The present study mainly relates to the creative industries as trend forecasting's sphere of action, which is applied in product development and innovation processes and functions as guidance and decision making aid (see: Brannon 2010). Trend forecasters claim to be sensitive towards changes and detect them before others do. One principal method is the constantly 'scanning' of social, cultural, political, and environmental changes. On basis of their findings, they develop a vision of a future world and deduct forecasts for certain branches or areas (e.g., fashion, colour, or interiors).

This field of trend forecasting, as being based more on intuition and on seemingly arbitrary approaches and methodological inconsistency, stays more offside the scholarly futures studies community and finds less academic attention.

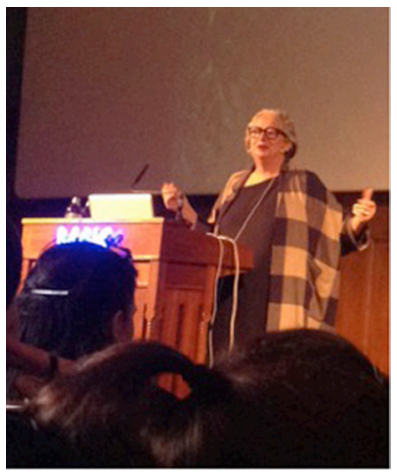

\section{Trend forecasting in contemporary design debates}

Today design increasingly functions as decision-making capacity and functional leader. Design is discussed as - and also aims to be in practice - a force of change, and a driver and creator of our culture that is "critical" (DiSalvo 2012; Dunne 2005), "activist" (FuadLuke 2009), "political" (Fry 2011; Wills 2013), "fictional" (Sterling 2010), and "frictional" (Mallol 2010).

Current design debates are concerned with the changing notion of design being a force crafting the future, becoming a change agent and opting for design holding discursive and normative power. Recent conferences put these issues on the forefront of their topics. ${ }^{2}$ Major discussion points are what influence design exerts on culture, how it shapes future and by which mechanisms it is able to implement this influence. Interestingly trend forecasting, innately dealing with future and change, is rarely considered in this context. Nevertheless, within design studies, an upcoming interest in futures studies and its different sub-fields is noticeable, especially in the area of design research and design methods (see: Irmak 2005; Brunini 2011; Evans 2011; O'Hara 2013). These writings share the same understanding and use of futures studies or trend forecasting; they remain

${ }^{2}$ See for instance: Crafting the Future (Academy of Design 2013); Social Design: Public Action. (Feireiss \& University of Applied Arts Vienna 2013); Design Activism and Social Change, Design (Design History Society \& Julier 2011); Negotiating Future - Design Fiction (Swiss Design Network 2010). 
considering trend forecasting as a methodological inspiration or toolbox for the design process.

Victor Margolin (2007) is one of the few who shows interest in futures studies and trend forecasting in the context of design studies' debate on design's impact on change and future, when he discusses how designers can gain more autonomy, discursive power and set the social agenda. However, also his view on trend forecasting remains on the obvious 'tool-delivering'-consideration of forecasting, as he promoted that futures studies could aid designers to be better prepared for the future as it could deliver tools helping designers formulating their own visions. Recently, also Cameron Tonkinwise (2014) touched trend forecasting's application for design. In his opinion trend forecasting can be used by design (studies) for information on possible futures, to generate evaluation criteria for design decisions, or as method to develop own future scenarios. In the end, it is again design, which is regarded as the one who makes the future (ibid.: 17).

This paper does not want to diminish these approaches of taking futures studies into account, but suggests going beyond this established connection. Seeing forecasting solely as an information provider of future developments, copying its methods and tools in order to use them within design, delivers an approvable, but limited frame. Shouldn't we ask ourselves if shaping the future already takes place by the practice of trend forecasting as such? To put it in other words: not only the designer or client who uses forecasting information shapes the future, but the practice of trend forecasting can itself be a generator of change, and therefore holds discursive and political power. As we have seen, current design studies' debates on design and its future capacity do not move forward to the idea that the practice of trend forecasting holds normative power within itself. This perspective still remains unacknowledged.

One reason for a low estimation of trend forecasting from this perspective might be that the practice of trend forecasting as such, as well as its impact and entanglement in our culture, is under-researched. As there are only a few empirical or critical theoretical examinations of the phenomenon of trend forecasting, only sparse and partial knowledge of trend forecasting's cultural role and agency is available. Most examinations stay on the surface of this profession and focus mainly on fashion forecasting or remain a commercial critique (see: Giertz-Mårtenson 2006; Chiaroni 2009). This current state of research is suggestive of considering trend forecasting still as commercial style advice, which is largely unworthy of serious academic examination.

\section{The trajectory of trend forecasting}

In recent years, some other critical examinations of trend forecasting appeared, (see: Fredriksson 2008; van Montfoort 2011), which shows that there is an interest in analysing this practice. Nevertheless, trend forecasting's growing dissemination and spread of influence beyond fashion remains unacknowledged and is not fairly reflected in academic analyses nor in design debates - a gap the PhD project in progress aims to close.

Although the growing entanglement of forecasting in today's culture took place largely unnoticed by critical studies, in business it has been widely applied. The empirical research showed that trend forecasting is far more than a style-selling-advice practice, exceeds its original fashion advice orientation and is having an effect on major operators of society. This change in the trend forecasting industry is, for instance, mirrored in the enlargement and diversification of clients beyond fashion or other core design businesses. This spread 
was highly visible at one trend research agency, where parts of the ethnographic fieldwork took place. A wide range of clients makes use of their visions and trends: political parties, bank institutes, hospitals, economic chambers of commerce, food producers, energy suppliers, hotels.

Nowadays, trend forecasting leads as a matter of course projects concerned with transforming corporate cultures, or with developing holistic future ideas of a country's society and identity. This shows that trend forecasting has penetrated well beyond the product worlds to society as a whole. Trend forecasting becomes an influential opinion and is thus political.

\section{Conclusion}

This paper points to an evident research gap in examining the phenomenon of trend forecasting and describing its power and influence it withholds in today's culture. This gap is considered being the reason for trend forecasting's low estimation and examination within current design discourse on design's future and change capabilities.

An integration of such an enlarged understanding of trend forecasting in design studies could deliver a fruitful perspective or become a possible threat to design studies. An opportunity could arise; as such a consideration of trend forecasting could reduce design studies' 'blindness' (or could we dare to say ignorance) and hierarchical attitude to other disciplines' power and agency. As discussed, the inherent impact of trend forecasting on culture and change remains unacknowledged by design debates, although trend forecasting operates in realms similar to design's enlarged sphere of influence on future and change making processes. Tonkinwise (2014) argues that design studies' research is insufficiently directed towards non-design practices. A look over the boundaries of design to the phenomenon of trend forecasting would meet this demand and generate larger understanding about change agents, practices with directive power on culture, society and stuff of our time.

Considering design studies' current pluralism (Tonkinwise 2014), the integration of trend forecasting as another discipline in design studies could simultaneously create a threat. We should take this peril into account and ask if we over-expand the design discourse even further if we bring the practice of trend forecasting in? Will this approach overextend the pluralism of design studies and notions of design even more and hence shifting design studies to an arbitrary and meaningless accumulation of approaches and methods? Or will it contribute to a (necessary) shift in understanding changes in the practice of design, in what design actually is, and subsequently contribute to re-gauging design studies' assignment?

Following Herbert Simons' primal definition of design "Everyone designs who devises courses of action aimed at changing existing situations into preferred ones." (Simon 1996: 111), we can establish a link between the practice of design and trend forecasting. Devising means nothing other than creating, making, thinking up something, or we could say envisioning. Envisioning situations, thus not necessarily things, providing guidance in today's world of possibilities ((Dilnot 2013) - in short mediation - this is nothing else trend forecasting provides.

Is forecasting a form of design now? Is it perhaps a future form of design, a necessary practice our culture has the need for? Is this the reason why forecasting is spreading and becoming more than a prescriptive style advice? 
In order to answer these questions, we first have to transcend viewing forecasting a commercial practice, which is just gathering trends and selling them, but rather a phenomenon of our time that concerns how we deal with the future and a practice holding normative and discursive power. This paper advocates that only by an in-depth examination of trend forecasting a necessary holistic understanding of this phenomenon can be developed in order to effectively engross these issues.

\section{References}

Academy of Design (2013) Crafting the Future: 10th European Academy of Design Conference, April 17-19 2013 in Gothenburg.

Brannon, E. (2010) Fashion forecasting, 3rd edition, New York: Fairchild Books.

Brunini, N. (2011) The Role and Value of Trend Reports for Product Designers, University of Cambridge.

Chiaroni, K.M. (2009) 'Fashion and Design Trend-forecasting: Can Commerce Meet Art and Prophecy in the Global Marketplace?', International Journal of the Arts in Society, Volume 4(4), pp.71-80.

Cole, S. (2001) 'Dare to Dream: Bringing Futures into Planning', Journal of the American Planning Association, 67(4), pp.372-383.

Design History Society \& Julier, G. (2011) Design Activism and Social Change, Design History Society Annual Conference. 8.-10.9.2011 Barcelona, Available at: http://www. historiadeldisseny.org/congres/ [5 May 2013].

Dilnot, C. (2013) Crafting the Future, Keynote speech at the conference: Crafting the Future: 10th European Academy of Design Conference, April 17-19 2013 in Gothenburg. DiSalvo, C. (2012) Adversarial design, Cambridge, Mass: MIT Press.

Dunne, A. (2005) Hertzian tales: electronic products, aesthetic experience, and critical design, 2005 ed., Cambridge, Mass: MIT Press.

Evans, M. (2011) 'Empathizing with the Future: Creating Next-Next Generation Products and Services', The Design Journal, 14(2), pp.231-251.

Feireiss, L. \& University of Applied Arts Vienna (2013) International Symposium: Social Design: Public Action, Austria, Wien. 26.-27.9.2013, Available at: http://socialdesign.ac.at/ public-action/ [21 Oct 2013].

Fredriksson, C. (2008) 'Trend Analysis: For Fashionistas Only?', ETN: JOB, Etnologisk skriftserie Etnologiska institutionen, Lunds universitet, (5), pp.83-90.

Fry, T. (2011) Design as politics, New York: Berg.

Fuad-Luke, A. (2009) Design activism: beautiful strangeness for a sustainable world, London ; Sterling, VA: Earthscan.

Giertz-Mårtenson, I. (2006) Att se in i framtiden: En studie av trendanalys inom modebranschen (Looking into the Future: A Study of Fashion Forecasting), MA Thesis. Stockholm University.

Irmak, O. (2005) 'Applying the Futures Studies Approach to Design', In Proceedings of the 6th International Conference of the European Academy of Design, Bremen, 29-31 March, Available at: http://comments.gmane.org/gmane.comp.hci.phd-design/7043 [19 Dec 2013]. Mallol, M.G. (2010) 'Displaying f(r)iction. Design as Cultural Form of Dissent', In Swiss Design Network, (ed.) Negotiating futures - design fiction, 6th Swiss Design Network Conference, October 20-30, 2010 in Basel, Basel: Swiss Design Network, pp. 106-117. Margolin, V. (2007) 'Design, the Future and the Human Spirit', Design Issues, 23(3), pp.4-15. Van Montfoort, F. (2011) Seers of the new and their hip apostles - On trend forecasting, postmodern cults and the re-enchantment of western society, Bachelor Thesis Cultural Anthropology, University of Amsterdam.

O'Hara, C.E. (2013) 'Transdisciplinary Practice: Using Futures Studies to Envision 
theme 6

open strand

Innovative Design', The International Journal of the Constructed Environment, 2(4), pp.185-194.

Simon, H.A. (1996) Sciences of the Artificial, 3rd edition, The Mit Press.

Sterling, B. (2010) Design Fiction: Beyond The Beyond, Available at: http://www.wired. com/beyond_the_beyond/category/design-fiction/ [3 Nov 2010].

Swiss Design Network (ed.). (2010) Negotiating futures - design fiction, 6th Swiss Design Network Conference, October 20-30, 2010 in Basel, Basel: Swiss Design Network.

Tonkinwise, C. (2014) 'Design Studies - What is it Good For?' Design and Culture, 6(1), pp.5-43. 